\title{
Finding a solution to the organ shortage
}

$\mathrm{F}$ ew topics have attracted so many authors writing with such remarkable verve and conviction to no substantial effect as the question of what to do about the shortage of organs available for transplantation. For the better part of four decades, supply has not kept pace with demand. The shortage has not yielded incremental policy changes. Perhaps we need to think far outside the box about donor eligibility. It is time to consider a strategy that seeks to maximize the pool of potential donors through a twostep process of consent to preserve and donate for those who die outside hospital. ${ }^{1}$

Let's begin with the numbers. Spain has the world's highest rate of donation, with 35 per million population; the United States has 26 per million, although some states achieve higher rates, and Canada is at 15 per million, about the same as Australia (International Registry in Organ Donation and Transplantation: www.irodat.org).

The continuing growth in demand in North America is fuelled by an aging population, increased longevity, higher rates of obesity associated with organ failure, and improvements in the efficacy of organ transplantation, especially for sicker and fragile patients. The supply of organs from cadavers has remained flat for years.

Efforts to increase public awareness about cadaver donation have done little to improve donation rates. ${ }^{2}$ Paired exchanges for kidneys linking willing donors with suitable matches have helped reduce the shortage a bit. But lethal shortage remains the reality. ${ }^{2}$

In recent years, ethical and policy concerns have shifted from efforts to

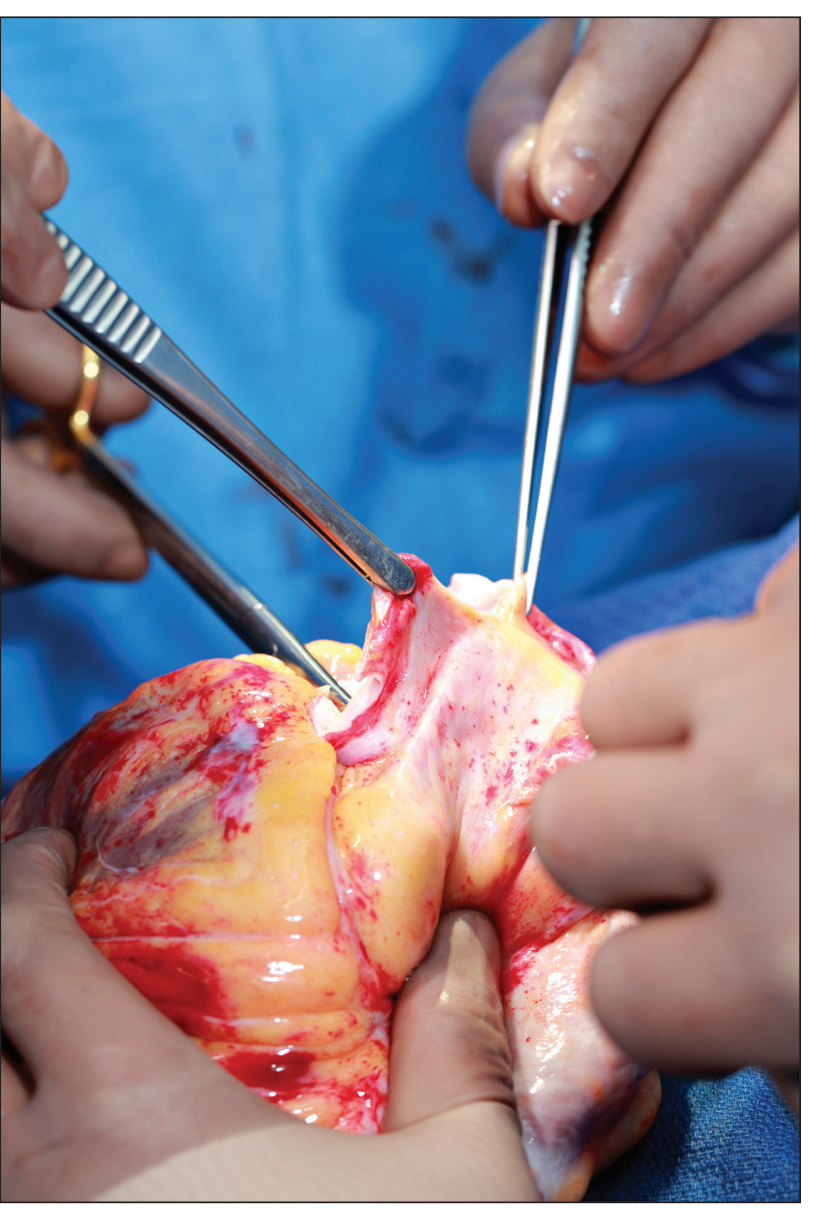

Another policy idea that has been around for many years is to shift cadaver procurement from an opt-in to an opt-out system. Some nations, including Spain, Belgium, France, Austria and Greece, have adopted this policy. ${ }^{4}$ Scotland and Wales as well as Iceland are or soon will try "presumed consent." 5,6 Still, there has been no movement to implement this policy in North America.

Yet another idea is to broaden the pool of potential cadaver donors. Some argue that brain death is too restrictive a requirement and that donor eligibility should be expanded to include a "persistent vegetative state" or a decision by a potential donor who is soon to die — death by donation. ${ }^{7}$ But adjusting the criteria for brain death is exceedingly risky. For decades, public support for donation has hinged on honouring the dead donor rule - no donation before determination of death.

tweak the ethical framework governing cadaver donation from an opt-in, voluntary, altruistic policy to heated debates about how to modify the framework to receive more organs. Some believe that markets involving payment to people willing, upon their deaths, to make an organ available hold the answer to increasing the supply. But these payments to the living would only exacerbate the fear that life-saving medical treatment would not be aggressive for those indicating their willingness to make organs available. In addition, many religions do not support markets in or payments for body parts, living or dead, thereby making the likelihood of market schemes unlikely. ${ }^{3}$
Patients in a persistent vegetative state or who have consented to death by donation are not dead according to cardiopulmonary criteria. Letting people serve as donors who are choosing their own way to die or moving the line on the criteria for brain death is likely to stoke public fears and distrust. Even with the advent of physician-assisted death, linking death to organ donation is unlikely to be permitted.

Markets for donated organs, presumed consent and shifting the line between life and death to permit cadaver donation are not likely to come to pass in Canada or the US. What then? Legislation could be enacted instituting a policy of seek- 
ing permission to preserve organs for donation in a dead body when death occurs outside a hospital intensive care unit. ${ }^{1}$

In the US and Canada, the overwhelming majority of deaths occur unexpectedly, outside hospital. These deaths are pronounced on the basis of cardiopulmonary death. Uncontrolled donation after circulatory determination of death - that is, dying from a cardiac death that is not medically monitored - requires initiation of organ preservation quickly after death. A few European programs initiate organ preservation and recovery without requiring explicit consent. ${ }^{8}$ But, a nonconsensual approach is not likely to be accepted by the US and Canadian public.

Rather than attempt to secure permission for organ donation from shocked and emotionally distraught family and friends, a two-step approach that exhibits appropriate respect for family and next of kin of the newly deceased might greatly expand the potential donor pool. ${ }^{1}$ The requests to preserve organs for possible donation could be made without actually requesting consent opportunity to consider organ donation at a later time must end.

Admittedly, not all deaths will be suitable for organ procurement. However, even if no more than a fraction of all deaths outside hospital produced permission to preserve, the pool of potential donors would be greatly expanded. The real costs would be in educating first responders to ask for permission to preserve, providing equipment and training to first responders, and public relations campaigns aimed at the general public to prepare it for the question about preservation. Because large numbers of Americans and Canadians say they wish to donate, the chance of seeing a real boost in cadaver kidneys, and perhaps other organs or tissues, is high. Is a respectful, two-step, strategy likely to be physiologically practicable? The two challenges are pronouncement of death and preservation until reaching a hospital.

In the case of cardiac death, cessation of circulation and ischemic injury to organs are the main reasons that organ donation is impossible. By continuing cardiac resuscitation, organs may be protected. Studies show that kidneys can be successfully used for

\section{Organ shortage is likely to continue to increase in the near future}

to organ donation. That consent could be made later at a hospital, following usual protocols. Relatives, family, partners or even friends could give permission, not for donation, but solely to preserve organs after cardiac death. This would be important if family and friends knew of the deceased's intent to donate or if a donor card was found. The goal of expanding the pool of donors must be respectful of the psychological vulnerability of family and friends after an unexpected death. ${ }^{9}$ No pressure or coercion should be used; at any sign of a negative response, attempts to secure the transplantation if in-situ organ "resuscitation" perfusion is carried out quickly after death. ${ }^{10,11}$ At arrival, first responders would attempt cardiopulmonary resuscitation until they declare it futile, in accordance with regional policies. Permission to preserve would then be sought from family or friends. If granted, the deceased would be transported to a hospital while chest compressions, mechanical ventilation, cannulation and administration of intravenous fluids continued. The results of follow-up with such kidneys meet generally accepted criteria for graft survival and function. However, developing screening criteria using age, comorbidity, weight and other factors in initiating requests to preserve could improve graft success rates. ${ }^{12}$

Organ shortage is likely to continue to increase in the near future. We need a way to expand the donor pool that is consistent with voluntary, altruistic ethos. A two-step process of consent aimed at out-of-hospital cardiac deaths using consent to preserve and later, at the hospital, consent to donate, would likely expand the pool of potential donors. Because such an approach is consistent with existing norms governing cadaver organ donation, it merits serious consideration.

\section{Arthur L. Caplan PhD}

Division of Medical Ethics, NYU Langone Medical Center, New York, NY

\section{References}

1. Wall SP, Plunkett C, Caplan AL. A potential solution to the shortage of solid organs for transplantation. JAMA 2015: 313;2321-2.

2. Knoll GA, Tinckham KJ. Organ donation and transplantation: the view from Canada. Transplantation 2015:99;2231-3.

3. Caplan AL, McCartney JJ, Reid DP, editors Replacement parts. Washington, DC: Georgetown University Press; 2015

4. Shepherd L, O'Carroll RE, Ferguson E. An international comparison of deceased and living organ donation/transplant rates in opt-in and opt-out systems: a panel study. BMC Med 2014:12;131.

5. Koffman G, Singh I. Presumed consent: the way forward for organ donation in the UK. Ann R Coll Surg Engl 2011:93;268-70.

6. Runarsdottir K, Olafsson K, Arnarsson A. Public attitudes towards presumed consent in organ donation in Iceland. Laeknabladid 2014:100;521-5.

7. Sade RM, Boan AD. The paradox of the dead donor rule: increasing death on the waiting list. Am J Bioeth 2014;14:21-3.

8. Rudge C, Matesanz R, Delmonico FL, et al. International practices of organ donation. Br J Anaesth 2012:108;i48-55.

9. Ghorbani F, Khoddami-Vishteh HR, Ghobadi O, et al. Causes of family refusal for organ donation. Transplant Proc 2011;43:405-6.

10. Morrissey PE, Monaco AP. Donation after circulatory death: current practices, ongoing challenges, and potential improvements. Transplantation 2014:97;258-64

11. Hosgood SA, Barlow AD, Dormer J, et al. The use of ex-vivo normothermic perfusion for the resuscitation and assessment of human kidneys discarded because of inadequate in situ perfusion. $J$ Transl Med 2015:13;329.

12. Bon D, Chatauret N, Giraud S, et al. New strategies to optimize kidney recovery and preservation in transplantation. Nat Rev Nephrol 2012:8;339-47.

This article has been peer reviewed.

CMAJ 2016. DOI:10.1503/cmaj.151260 